\title{
Estimation of Genetic Parameters of Biomass Production and Composition Traits in Miscanthus Sinensis Using a Staggered-start Design
}

\author{
Raphael Raverdy \\ INRAE BioEcoAgro \\ Emilie Mignot \\ GCIE Picardie \\ Stéphanie Arnoult \\ GCIE Picardie \\ Laura Fingar \\ INRAE BioEcoAgro \\ Guillaume Bodineau \\ INARE GBFOr

\section{Yves Griveau} \\ INRAE IJPB \\ Solenne Volant \\ INRAE BioEcoAgro \\ Maryse Brancourt-Hulmel ( $\triangle$ Maryse.Hulmel@inrae.fr ) \\ INRAE BioEcoAgro https://orcid.org/0000-0002-8679-7537
}

\section{Research Article}

Keywords: Broad-sense heritability, variance components, age effect, climate effect, genetic and phenotypic correlations

Posted Date: December 30th, 2021

DOI: https://doi.org/10.21203/rs.3.rs-354838/v1

License: (c) (i) This work is licensed under a Creative Commons Attribution 4.0 International License. Read Full License 


\title{
1 Estimation of genetic parameters of biomass production and
}

\section{2 composition traits in Miscanthus sinensis using a staggered-start}

\section{3 design}

4 Raphaël Raverdy ${ }^{1}$, Emilie Mignot ${ }^{2}$, Stéphanie Arnoult ${ }^{2}$, Laura Fingar ${ }^{1}$, Guillaume Bodineau ${ }^{3}$, Yves Griveau ${ }^{4}$,

5 Solenne Volant ${ }^{1}$ and Maryse Brancourt-Hulmel ${ }^{1}$

${ }^{1}$ BioEcoAgro Joint Research Unit, INRAE AgroImpact, Université de Liège, Université de Lille, Université de Picardie Jules Verne, 80203, Estrées-Mons, France

${ }^{2}$ GCIE-Picardie, INRAE, UE, 80203, Estrées-Mons, France

${ }^{3}$ GBFOr, INRAE, UE, Ardon, France

${ }^{4}$ Institut Jean-Pierre Bourgin, INRAE, AgroParisTech, CNRS, Université Paris-Saclay, 78000, Versailles, France

\section{Corresponding Author}

Maryse Brancourt-Hulmel

Email: maryse.hulmel@inrae.fr

\begin{abstract}
Traits for biomass production and composition make Miscanthus a promising bioenergy crop for different bioconversion routes. They need to be considered in miscanthus breeding programs as they are subjected to genetic and genetic $\mathrm{x}$ environment factors. The objective was to estimate the genetic parameters of an $M$. sinensis population grown during four years in two French locations. In each location, the experiment was established according to a staggered-start design in order to decompose the year effect into age and climate effects. Linear Mixed Models were used to estimate genetic variance, genotype x age, genotype $\mathrm{x}$ climate interaction variances and residual variances. Individual plant broad-sense heritability means ranged from 0.42 to 0.62 for biomass production traits, and were more heritable than biomass composition traits with means ranging from 0.26 to 0.47 . Heritability increased through time for most of the biomass production and composition traits. Low genetic variance along with large genotype $\mathrm{x}$ age and genotype $\mathrm{x}$ climate interaction variances tended to decrease the heritability of biomass production traits for young plant ages. Most of the production traits showed large interaction variances for age and climate in both locations, while biomass composition traits highlighted large interaction
\end{abstract}


variances due to climate in Orléans. The genetic and phenotypic correlations between biomass production and composition traits were moderate and positive, while hemicelluloses were negatively correlated with all traits. Efficient genetic progress is achievable for miscanthus breeding when plants get older. The joint improvement of biomass production and composition traits would help provide a better response of miscanthus to selection.

\section{Keywords}

Broad-sense heritability, variance components, age effect, climate effect, genetic and phenotypic correlations

\section{Introduction}

High-yielding crops with low-nutrient inputs and minimal negative environmental impacts are required for sustainable agriculture [1,2]. As such, species from the Miscanthus genus are perennial C4 grasses native to East Asia and identified as promising lignocellulosic biomass in Europe and North America [3-6]. Therefore, this crop is a feedstock for a broad range of applications: heat and electricity production, gardening and animal bedding, as well as recent applications such as biofuel and biomaterial production [7-9].

Miscanthus $\times$ giganteus $($ M. $\times$ giganteus $)$, an interspecific hybrid between M. sacchariflorus and M. sinensis, is currently being used for most biomass production in Europe and North America with a single clone $[10,11]$. This clone can be grown for 20-25 years in the field, for the oldest plantations [4]. However, growing this single clone is risky, because pests and diseases could spread in non-native areas and economically threaten the overall biomass production. Moreover, the narrow genetic base of this interspecific hybrid [12] and the sterility of the cultivated clone hampers its breeding. Therefore, the development of new miscanthus cultivars is targeted with a wide adaptation to a range of different environments [13, 14].

The diploid Miscanthus sinensis and the tetraploid Miscanthus sacchariflorus represent substantial genetic and undomesticated diversity, making them capable of adapting and growing in various geographic areas $[15,16]$. The former has a high yield potential and is adapted to drained soils, while the latter develops long rhizomes with an ability to spread, especially in wetland areas $[15,17]$, which is not desirable due to the risk of it becoming invasive. For these reasons, $M$. sinensis is more suitable for improving biomass production in arable lands.

The genetic improvement of $M$. sinensis will thus serve to enhance its own potential biomass production as well as $M . \times$ giganteus yield, while preserving the sterility of the new varieties in order to prevent potential invasiveness $[13,18]$.

M. sinensis exhibits considerable intraspecific variability, with major genetic groups originating from regions across China, Korea and Japan [19-21]. The breeding of new miscanthus cultivars would make it possible to 
extend the genetic base in miscanthus breeding programs of western countries where it is mainly obtained from ornamental accessions originating from Japan $[18,20]$. This would be possible by crossing distinct ornamental cultivars or exploiting wild available germplasm [13, 18, 22].

To meet the requirements of miscanthus applications, high-yielding cultivars are needed with a quality well suited for each application targeted [13]. For these reasons, biomass production and biomass composition traits have to be evaluated across contrasted environments. The phenotype or expression of each trait differs according to the available genetic variability, itself determined by the genetic material studied. It also differs according to the environmental variability, determined for the years and locations considered.

Many studies have evaluated M. × giganteus, M. sinensis or M. sacchariflorus genotypes (accessions, hybrids, etc.) for yield and morphological traits. For these traits, genotype $\mathrm{x}$ year, genotype $\mathrm{x}$ location or both interactions have been highlighted in miscanthus [22-27]. Other studies have found the same trends while evaluating miscanthus biomass composition traits [26, 28-31].

This suggests that genetic variability and environmental variability are key features which must be taken into account in the evaluation of traits for miscanthus breeding. For that reason, their characterization based on the study of a mapping population is required in order to determine the proportion of phenotypic variance that is the result of genetic factors, known as broad-sense heritability, for each trait. In addition to the investigation of the phenotypic correlations between species [32, 33], it would provide a thorough investigation of the genetic correlations between biomass composition traits, and their relationship with yield and yield-component traits.

Miscanthus genetic parameters of biomass production and composition traits were studied either separately or together, prior to molecular-trait associations (GWAS) or genotypic performance evaluations [34-38]. Prior to QTL studies, they were evaluated for the biomass production or composition traits, separately [31, 39, 40]. Successive years were considered for these studies, rarely for more than one location. Only Clark et al. [38] have evaluated M. sinensis accessions in six locations and have highlighted combined genetic group $\mathrm{x}$ location and genotype within genetic group $\mathrm{x}$ location effects that represent a substantial proportion of the total variation for biomass yield (32\%) in the third year after planting.

The objectives of this study were to estimate the genetic parameters, genetic and phenotypic correlations in terms of biomass production and composition traits together, during four consecutive years in a diploid biparental M. sinensis population in two contrasted locations. We predicted that these genetic parameters and correlations would vary according to genetic and environmental variability. Environmental variability is itself determined by specific conditions such as location and year, and the year encompasses the age and climate effects in a perennial 
crop such as miscanthus. For that purpose, the population was tested according to a staggered-start design [41] that established the population twice in 2014 and 2015 in both locations. With such a design, the "year" effect can be decomposed into an "age" effect and a "climate" effect $[42,43]$. To date, it is the first study in miscanthus which estimates the genetic parameters and correlations when considering both biomass production and composition traits, and distinguishes within the year, age and climate effects. This will substantially broaden knowledge of the genetic evaluation of biomass traits, according to the effects of age, climate or location.

\section{Materials and Methods}

\section{Plant material}

The mapping population was generated by crossing two diploid ornamental M. sinensis cultivars, "Malepartus" (Mal) and "Silberspinne" (Sil), to obtain an F1 progeny. These two parents were purchased in a French nursery for a previous study [44] and their initial provenance was identified to be from central and southern Japan [20, 21]. They were then evaluated in the field within a set of 21 miscanthus clones [26, 44]. They were selected for their highly contrasted plant stem numbers, and then reciprocally crossed in isolated greenhouses during the fall of 2007, at the INRAE BioEcoAgro research center of Estrées-Mons in Northern France. All the seeds resulting from the cross were then stored in suitable packaging at $4^{\circ} \mathrm{C}$. From 2012 to 2015 , each seed was germinated in-vitro and the corresponding plant was propagated in-vitro according to a protocol of shoot organogenesis and regeneration [45]. This provided clonal replicates of each single genotype originating from a seed. Then, all seedlings were planted in a greenhouse that offered suitable growing conditions before being transplanted to a field. An average of four replicates was finally obtained per genotype, with variations for some genotypes due to variable genotype ability for in-vitro propagation.

\section{Experimental Design and Planting}

The experimental design of the trial was a staggered-start design [41], established in two different French locations mainly contrasted by their soil and climatic conditions. The first site was located at the INRAE GCIE experimental unit of Estrées-Mons (Somme, $49^{\circ} 53^{\prime} \mathrm{N}, 3^{\circ} 00^{\prime} \mathrm{E}$ ) and characterized by a deep loam soil (Orthic Luvisol, WRB) while the second one was located at the INRAE GBFOr experimental unit in Orléans (Loiret, 47²49'N, $1^{\circ} 54^{\prime} \mathrm{E}$ ) and offered a sandy soil (Dystric Cambisol, WRB). For each location, the field trial consisted in a staggered-start design where two groups of genotypes were established in two subsequent years, according to two adjacent plots in the field (one plot per year). The first group of genotypes was established in 2014 and coded G1, while the 
second group of genotypes was established in 2015 and coded G2 (Fig. 1). The first group G1 was observed for a four-year period and the second group G2 for a 3-year period. In Estrées-Mons, 159 replicated genotypes, including the parents, were distributed across each plot, with most genotypes being common between the two establishment years (Table 1). In Orléans, 106 replicated genotypes, including the parents, were established in each plot, with in addition a set of genotypes common to the two establishment years (Table 1). In both locations, each of the two plots was organized with single plants in an incomplete randomized block design, with genotypes being replicated in four of the five blocks on average. Therefore, each of the two staggered-start designs was composed of two incomplete randomized block designs. The single-plants were equally spaced within and between rows 1 meter apart, which lead to a plant density of 1 plant per $\mathrm{m}^{2}$. To ensure an equal competition effect between plants along the trial, a border row was planted on each side of the plots that contained repeated genotypes of the population. After transplanting, the field trial was watered and drip irrigation was installed, in both years and locations, thus supplying sufficient water for the overall duration of the trial. No fertilizers were applied and weed management was carried out using a hoe whenever necessary. Plants that did not survive the first year were replaced by plants of the same age that were kept in a nursery near the trial.

The strength of the staggered-start design made it possible to decompose the "year" effect into "age" and "climate" effects (Fig. 1). For example, when considering the "year" 2017 in one location, G1 and G2 were contrasted by the "age" effect, because G1 plants were three-year old while G2 plants were only two-year old. Thus, the age effect was decomposed based on the year considered, in which a given climate condition occurred. Plants with the same "age" of 3-year old genotypes were then considered, for instance, with G1 observed in 2017 and G2 in 2018: G1 and G2 were now distinguished by the "climate" effect, because G1 plants were evaluated during the year 2017 and G2 plants during 2018. Therefore, the "climate" conditions that occurred during each "year" were considered using plants of the same "age". All these decompositions were applied in each location to all biomass production and composition traits in order to assess the corresponding genetic parameters, genetic and phenotypic correlations. It can be noted that the analysis of these two kinds of data required two different statistical models as described later in the statistical analysis section.

\section{Climatic conditions according to plant cycle determined per year and location}

145 As reported previously, the staggered-start design was established in two different locations, each one characterized by specific soil and climate conditions. Weather indicators were calculated according to five periods of the plant cycle determined on Malepartus which is one parent of the population. These periods were determined 
for each year in which the population grew, by considering each location separately (Tables S2a and S2b). The pre-emergence phase was coded as Period 1 and lasted from senescence in the fall of year N-1 to shoot emergence in year $\mathrm{N}$ (and accordingly, this period was not available for the first year). Period 2 lasted from shoot emergence to floral transition, i.e. which corresponded to the differentiation of the terminal vegetative apex into a panicle and was determined as the date of the first stem that showed the transition to floral stage. This date was determined according to Hou et al. (submitted to BioEnergy Research). Period 3 lasted from floral transition to panicle heading and Period 4 from panicle heading to senescence. Period 5 slightly contrasted with the other periods that were identically determined in both locations: in Estrées-Mons, it started with senescence and ended on the date of the first winter frost, while it ended on the harvest date in Orléans. This was due to the fact that winter frost always occurred after senescence in Estrées-Mons and therefore shortened the plant cycle, while no winter frost occurred in Orléans for all the years observed.

In each location, weather indicators were recorded daily in a meteorological station located at a short distance from the trial, and downloaded from the CLIMATIK database (INRAE AGROCLIM, 2020). The weather indicators were as follows: air minimum temperature (MinT), air maximum temperature (MaxT), air mean temperature (MeanT), soil minimum temperature (MinTs), precipitation (Prec_M), mean humidity (MeanH), vapor-pressure deficit (VPD), maximum vapor-pressure deficit (VPD_M), Penman potential evapotranspiration (ETPP), photosynthetically active radiation (PAR), cumulated growing degree-days (CGDD). Their mean was calculated for each year in each location according to the five periods of the plant cycle previously defined (Tables S3a and S3b). In addition, cumulated precipitation (Prec_S) was also determined.

\section{Phenotyping of biomass production and composition traits}

The phenotyping was carried out for five biomass production traits and six biomass composition traits (from which three traits were expressed as a percentage of dry matter, \%DM or cell wall, \%CW). In each location, the data was acquired over a four-year period, from 2014 for G1 and 2015 for G2. Each trait was named according to a miscanthus ontology, developed at the INRAE BioEcoAgro research unit of Estrées-Mons, thanks to the GnpIS multispecies integrative information system from the INRAE URGI of Versailles [46]. maximum height (HMax_cm) was measured in late fall from the ground to the highest panicle of the plant (if the 
(PSNb) was determined in late fall on each plant, by considering all stems with at least one ligulated leaf. Plant circumference $\left(\mathrm{C} 50 \_\mathrm{cm}\right)$ corresponded to the measurement, just before harvest, of the plant circumference $50 \mathrm{~cm}$ from the ground. The aboveground biomass yield (ABM_tDMha), expressed in tDM/ha, was calculated based on the fresh weight and dry weight of one plant (dry matter per ha) after the winter harvest late February.

The composition traits related to biomass quality were determined. For each plant, a representative sample of approximately $500 \mathrm{~g}$ of fresh matter was dried at $55^{\circ} \mathrm{C}$ for 4 days in a well-ventilated oven, and ground using a hammer mill grinder for it to pass through a $1 \mathrm{~mm}$ grid. Each resulting dry powder sample was then analyzed using the Near-infrared spectroscopy (NIRS) method for spectral assessment. NIR spectra were measured using an Antaris II - Thermo spectrometer and expressed in absorbance with a wavenumber range between $4000 \mathrm{~cm}^{-1}$ and $10000 \mathrm{~cm}^{-1}$ and a resolution of $4 \mathrm{~cm}^{-1}$. The corresponding spectra of the whole population were then analyzed using a Principal Component Analysis (PCA), in order to determine a calibration sample that included contrasted genotypes which best reflected the whole population for the year under consideration. This calibration sample was then biochemically analyzed in the Laboratoire Agronomique de Normandie (LANO), using the Van Soest method [47]. Each trait was estimated through NIRS predictions carried out by Partial Least Square (PLS) regression on near-infrared absorption spectra while considering the calibration sample. The validation of the predictions was then carried out based on independent samples of the population. Calibration and validation parameters are given in Table 2 for a range of biochemical composition traits for all the population genotypes. The following traits were considered, according to the total dry matter content or cell wall content: Neutral Detergent Fiber, which corresponded to the cell wall content (coded NDF_\%DM), Acid Detergent Fiber (ADF_\%DM), Cellulose (CL_\%DM; CL_\%CW), Hemicelluloses (HEM_\%DM; HEM_\%CW), Acid Detergent Lignin (ADL_\%DM; ADL_\%CW) and Ash (Ash_\%DM).

\section{Statistical analysis}

Phenotyping data was analyzed for each location separately. Two Linear Mixed Models [48] were carried out for the unbalanced datasets: Model 1 for the age effect modeling according to each year and Model 2 for the climate effect modeling according to each age (Fig.1). For the staggered-start design in Estrées-Mons, 159 genotypes were included, with 82 in common between the G1 and G2 groups of genotypes. As for the staggered-start design in Orléans, 106 genotypes were considered, with 59 in common between G1 and G2.

All production and composition traits were normally distributed and no data transformations were thus required prior to the analysis. To account for the age effect modeling (Model 1), a Linear Mixed Model was applied to each 
trait studied, considering each location and each year in which the progeny grew. It initially consisted of a full statistical model which took into account block and spatial effects using the "breedR" package implemented in the R software [49]. It accounted for the environment heterogeneity within each trial among the blocks and diagnosed spatially distributed patterns of remaining residual variations using variograms. The remlf90 function of the package, based on restricted maximum likelihood estimations, was used to estimate all variance components of the progeny.

$$
Y_{i j k l}=\mu+\alpha_{i}+\beta_{j}+(\alpha \beta)_{i j}+\delta_{l}+\varepsilon_{i j k l}(1)
$$

where $\mathrm{Y}_{\mathrm{ijkl}}$ represents the phenotypic value measured on plant $k$ of genotype $i$ at age $j$ in block $l ; \mu$ is the overall mean; $\alpha_{\mathrm{i}}$ is the random effect of genotype $i$; $\beta_{\mathrm{j}}$ is the fixed effect of age $j ;(\alpha \beta)_{\mathrm{ij}}$ is the random interaction between genotype $i$ and age $j$; $\delta_{1}$ is the effect of block $l$ and $\varepsilon_{\mathrm{jjkl}}$ is the random residual for plant $k$ of genotype $i$ at age $j$ in block $l$. An autoregressive spatial component was included in the model based on $\mathrm{x}$ and $\mathrm{y}$ coordinates in each plot in order to decompose the residual $\varepsilon_{\mathrm{ijk}}$ into a spatially dependent parameter, $\theta_{\mathrm{ikl}}$, for plant $k$ of genotype $i$ in block $l$, and an independent remaining residual [50].

This full model was compared with a sub-model with no decomposition of the residual term into spatially dependent and independent effects. It was also compared with another sub-model with no block effect but with the decomposition of the residual term into spatially dependent and independent effects. Based on the Akaike information criterion (AIC) [51] of each of the three models, the last one which dropped the block effect but took into account the spatial effect was found to have a lower AIC (i.e. better performance) in all data sets (Fig. S1) and was retained afterwards. In addition, each model detailed hereafter was initially tested on balanced datasets by considering the 82 common genotypes between G1 and G2 in Estrées-Mons. Then, each model was tested on unbalanced datasets using all genotypes, which were common and non-common between G1 and G2. As models applied to balanced and unbalanced datasets yielded very similar results, all the analyses were finally carried out on unbalanced datasets, thus including more genotypes. The Model 1 finally used was written as follows:

$$
Y_{i j k}=\mu+\alpha_{i}+\beta_{j}+(\alpha \beta)_{i j}+\varepsilon_{i j k}(1)
$$

where all the terms are described as previously without taking into account the block effect.

To account for the climate effect modeling (Model 2), the following Linear Mixed Model was applied to each studied trait, considering each location and each age of the progeny:

$$
Y_{i k l}=\mu+\alpha_{i}^{\prime}+\gamma_{l}+\left(\alpha^{\prime} \gamma\right)_{i l}+\varepsilon_{i k l}^{\prime}(2)
$$

where each term is similar to Model 1 except that age effect $\beta_{\mathrm{j}}$ is replaced by climate effect $\gamma_{1}$ of year $l$, and the interaction between genotype $i$ and age $j(\alpha \beta)_{\mathrm{ijj}}$ by the interaction between genotype $i$ and climate effect of year $l$ 
$\left(\alpha^{\prime} \gamma\right)_{\mathrm{il}}$. Note that the terms $\alpha_{i}^{\prime}, \varepsilon^{\prime}{ }_{i k l}$ and $\theta_{i k}^{\prime}$ were different from the effects given by the previous Model 1 because they were estimated based on different datasets.

The ratio of the genetic variance to the genotype $\mathrm{x}$ age interaction variance and the ratio of the genetic variance to the genotype $\mathrm{x}$ climate interaction variance were respectively computed based on corresponding variance components estimated using Model 1 and Model 2. For each trait, these ratios made it possible to determine the part of genetic determinism mainly due to stable genetic effect or genotype $\mathrm{x}$ age and genotype $\mathrm{x}$ climate interaction effects.

According to the two previous models, individual plant broad-sense heritability sensu lato values $\left(H_{s l}^{2}\right)$ were estimated using the following formulas:

For the age effect modeling according to each year (Model 1),

$$
H_{s l}^{2}=\frac{\sigma_{\alpha}^{2}}{\sigma_{\alpha}^{2}+\sigma_{\alpha \beta}^{2}+\sigma_{\varepsilon}^{2}}(3)
$$

where $\sigma_{\alpha}^{2}$ is the variance attributed to the genotype, $\sigma_{\alpha \beta}^{2}$ is the variance of the genotype $\mathrm{x}$ age interaction and $\sigma_{\varepsilon}^{2}$ is the residual variance.

For the climate effect modeling according to each age (Model 2),

$$
H_{s l}^{2}=\frac{\sigma_{\alpha^{\prime}}^{2}}{\sigma_{\alpha \prime}^{2}+\sigma_{\alpha \prime \gamma}^{2}+\sigma_{\varepsilon^{\prime}}^{2}}(4)
$$

Here, each term is similar to the previous formula, except $\sigma_{\alpha \prime}^{2}$ which is the variance of the genotype x climate interaction.

According to the two previous models again, progeny-mean broad-sense heritability values $[52,53]$ were also estimated for the age effect modeling (Model 1) and the climate effect modeling (Model 2), respectively, as:

$$
\begin{gathered}
H_{P i}^{2}=\frac{\sigma_{\alpha}^{2}}{\sigma_{\alpha}^{2}+\frac{\sigma_{\alpha \beta}^{2}}{J}+\frac{\sigma_{\varepsilon}^{2}}{J K}}(5) \\
H_{P i}^{2}=\frac{\sigma_{\alpha \prime}^{2}}{\sigma_{\alpha \prime}^{2}+\frac{\sigma_{\alpha \prime}^{2} \gamma}{L}+\frac{\sigma_{\varepsilon \prime}^{2}}{L K}}(6)
\end{gathered}
$$

Where $J$ is the number of ages considered, $L$ is the number of years with associated climates and $K$ is the mean number of replicates per genotype.

Genetic and phenotypic correlations between traits were then assessed, considering a given year with the age effect modeling (Model 1) or a given age with the climate effect modeling (Model 2). Genetic correlations were estimated using Equation 9 described in Howe et al. (2000) [54]. 
To calculate phenotypic correlations with individual values, Pearson correlation coefficients were computed using R package "stats" and visualized using the "corrplot" R package [55].

By considering the weather indicators determined for the five periods of the plant cycle for each year and each location, a Principal Component Analysis (PCA) and a subsequent Hierarchical Clustering on Principle Components (HCPC) were carried out using the "FactoMineR" R package [56].

\section{Results}

Biomass composition traits were generally less heritable than biomass production traits

\section{with substantial variations according to climate conditions and ages for all traits}

For each trait, the means of individual plant broad-sense heritability $\left(H_{s l}^{2}\right)$ and the means of progeny-mean broadsense heritability $\left(H_{P i}^{2}\right)$ were computed based on heritability values determined using each age effect for each year, or each climate effect for each age, with Model 1 or Model 2, respectively. Each location was considered separately (Table S1). This made it possible to know how much a trait was heritable, before analyzing their evolution while considering the age effect throughout the years or the climate effect throughout the ages. In Estrées-Mons, the biomass production traits were moderately to highly heritable, with means of individual plant broad-sense heritability ranging from 0.42 to 0.62 for estimates of Model 1 and from 0.43 to 0.52 for estimates of Model 2 (Table 3). Biomass composition traits were generally less heritable, ranging from 0.29 to 0.44 for estimates of Model 1 and from 0.26 to 0.47 of Model 2. In Orléans, the ranges were similar to those in Estrées-Mons, for estimates of both models and trait types (Table 3).

By considering the means of progeny-mean broad-sense heritability $\left(H_{P i}^{2}\right)$, which were more meaningful at clonal level, traits were highly heritable for both models and both locations, with the corresponding means ranging from 0.60 to 0.88 (Table S1). According to those means, the progeny-mean broad-sense heritability was around 1.5 to 2.5 higher than individual plant broad-sense heritability, most often with a higher difference for composition traits.

Lower genetic variances along with larger interaction variances explained the lower heritability values for biomass production traits at young plant ages 
year corresponded to younger plants, that were 2 years old and 1 year old according to G1 and G2, respectively. The corresponding genotype $\mathrm{x}$ age interaction variance (i.e. age effect) was larger for these young plant ages (Fig. 2a) as highlighted by the lower ratio of the genetic variance to genotype $x$ age interaction variance (Table 3 ). This ratio was even lower than 1 for aboveground biomass yield and lower than 2 for plant stem number and plant circumference in Orléans, respectively meaning that the extent of the genotype $\mathrm{x}$ age interaction variance was higher than the genetic variance or corresponded to more than $50 \%$ of it (Fig. 2a; Table 3). Accordingly, the resulting individual plant broad-sense heritability values $\left(H_{s l}^{2}\right)$ of production traits were generally lower in 2016 while they increased throughout the years. Canopy height, plant maximum height and aboveground biomass yield continuously increased until they reached a maximal heritability level above 0.50 in 2018 for both locations (Fig. 2a; Table S1). However, plant stem number in both locations and plant circumference in Estrées-Mons reached a maximum level one year earlier, in 2017 , with values of $0.45,0.56$ and 0.49 , for each case respectively (Fig. 2a; Table S1). When comparing the individual plant broad-sense heritability values obtained in 2018 to those obtained in 2016 in Estrées-Mons, the increase varied from 10\% to 30\% except for the plant stem number. In Orléans, this increase ranged from $30 \%$ to $80 \%$ (Table S1). Biomass composition traits were not so highly subjected to genotype x age interaction: consequently, the heritability values were higher in 2018 for Orléans, mainly because of an increase in genetic variance (Fig. 2b; Fig. S2a; Table 3; Table S1).

Model 2 was used to model the climate effect for successive ages: lower genetic variances were highlighted for a major part of production traits at age 1 than at older plant ages in both locations (Fig. 3a; Table 3). For this age, the genotype $\mathrm{x}$ climate interaction variance (i.e. climate effect) was evaluated according to $\mathrm{G} 1$ plants observed in 2015 and G2 plants in 2016: the associated ratio of genetic variance to genotype x climate interaction variance was often lower than for other ages, meaning that young plants were the most subjected to climate variations (Table 3). Thus, the related individual plant broad-sense heritability values $\left(H_{s l}^{2}\right)$ were generally higher at age 2 or age 3 . They increased to reach a maximum level above 0.50 at age 3 for canopy height and plant maximum height in both locations (Fig. 3a; Table S1). For the plant stem number and aboveground biomass yield, the maximal heritability was reached at age 3 in Orléans, with values of 0.56 and 0.53 , respectively. In Estrées-Mons, these traits showed the highest values, 0.47 and 0.50 respectively, at age 2 . When comparing the individual plant broadsense heritability values obtained at age 3 to those obtained at age 1, the increase ranged from $20 \%$ to $100 \%$ in each location, except for the plant stem number in Estrées-Mons (Table S1). 

climate in both locations while all composition traits showed large interaction variances according to climate in Orléans

326

The ratio of the genetic variance to genotype $\mathrm{x}$ age interaction variance, determined according to Model 1 , was relatively low for most of the production traits evaluated from 2016 to 2018 in both locations. For the plant stem number, plant circumference and aboveground biomass yield, this ratio ranged from 1.9 to 6.1 in Estrées-Mons and from 0.9 to 3.6 in Orléans (Table 3). The lower the ratio values, the more genotype $\mathrm{x}$ age interaction variance was associated to the genetic determinism of a trait, which meant that genotype $\mathrm{x}$ age interaction variances were substantial for these traits and conditions (Fig. 2a; Table 3).

The ratio of the genetic variance to genotype $\mathrm{x}$ climate interaction variance, determined using Model 2, was also generally low for the production traits evaluated from age 1 to age 3 and for both locations. In Estrées-Mons, it ranged from 2.2 to 5.0 when considering both heights at age 1 and age 2, while it ranged from 1.9 to 5.5 for plant stem number, plant circumference and aboveground biomass yield when considering all ages. In Orléans, the ranges of this ratio were relatively similar concerning the same traits (Table 3).

In contrast to Estrées-Mons, the biomass composition traits evaluated in Orléans showed large interaction variances according to the climate effect (Fig. 3b; Fig. S2b), as highlighted by the ratio ranging from 1.0 to 5.7 (Table 3). This ratio was especially low in 2017, which contributed to a decrease in heritability values compared to 2018 (Fig. 3b; Fig. S2b; Table 3; Table S1).

Accordingly, most of the production traits showed large interaction variances according to age and climate in both locations, while all composition traits showed large interaction variances according to climate in Orléans. Therefore, the corresponding heritability values were lowered.

\section{The climate conditions that occurred during the plant cycle explained the climate effect}

\section{between different years}

For each location, a Principal Component Analysis (PCA) was conducted to identify the weather indicators that contribute to the climate effect on the different traits observed over time. In Estrées-Mons, the first two principal components (PCs) accounted for $87.5 \%$ of the total variation in the correlation matrix, with PC1 explaining 75.2 $\%$ and PC2 explaining $12.3 \%$. In Orléans, those values were respectively 91.9\%, 78.8\% and 13.1\% (Fig. 4a and 4c). 
For both locations, eight weather indicators had high positive loadings $(>0.9)$ on the right-hand position of the PC1 first principal component (Fig. 4a and 4c). Those indicators were related to temperature (MinT, MeanT, MaxT for the air and MinTs for the soil), Penman potential evapotranspiration (ETPP), photosynthetically active radiation (PAR) and vapor-pressure deficit (VPD and maximal VPD_M). They were also highly correlated with each other. MeanH had a high negative loading (<-0.9), on the left-hand position of the PC1 first principal component (Fig. 4a and 4c). For both PCA, the PC2 second principal component was explained by the sum of precipitation calculated for each period and each year (Prec_S) as well as by the corresponding mean precipitation (Prec_M).

As for Estrées-Mons, the clustering of the coordinates on the first two PCA components of the individuals (i.e. periods according to year) divided them into six distinct clusters (Fig. 4b). Cluster 2 and cluster 4 were the only ones to include four years of a single period, which corresponded to Period 5 (from senescence to the date of the first frost day of the year) and Period 2 (from emergence to floral transition), respectively. Cluster 1 included the three available years for Period 1 before emergence. The year 2018 was very warm for Period 2, Period 4 and Period 5, which contrasted with all other years for each of these periods, especially in 2017 (Fig. 4b). This was particularly observed for two climate indicators related to air and soil temperatures (Table S3a). Therefore, these contrasted climate conditions between those years, for most of the periods related to the yield-building phase, partially accounted for the higher genotype $\mathrm{x}$ climate interaction variances observed for plant stem number, plant circumference and aboveground biomass yield.

In Orléans, the years of Period 1 and Period 5 were spread over two clusters (Fig. 4d). By definition, Period 5 stages in year $\mathrm{N}$ (from senescence in year $\mathrm{N}$ to winter harvest in year $\mathrm{N}+1$ ) overlapped with Period 1 stages in $\mathrm{N}+1$ (from senescence in year N-1 to emergence in year N). Three clusters included the four years of a single period. The climatic conditions that occurred in 2015 were relatively rainy before floral transition and after panicle heading, and very warm and dry during the floral transition (i.e. Period 3) (Table S3b). Such conditions during the floral transition were highly contrasted with the year 2016, for which lower temperatures and higher precipitation were observed than for other years. For Period 5, the year 2016 also contrasted with years 2015 and 2017, with lower precipitation and temperatures (Fig. 4d, Table S3b). Thus, the climatic variations between 2016 and other years were likely to affect plant growth differently and contributed to explaining the genotype x climate interaction, which was especially highlighted for plant stem number, plant circumference and aboveground biomass yield at ages 1 and 2 . 

traits and biomass composition traits, while they were moderate between both types of

383

384

\section{traits}

The genetic and phenotypic correlations were calculated in both locations, for each year - using age effect modeling (Model 1) - and each age - using climate effect modeling (Model 2). As they were relatively similar in all cases, they were illustrated in two cases: in the first case with year 2017 in Estrées-Mons (Fig. 5), the correlations corresponded to the relationships between the traits according to the age effect modeling (between age 3 for G1 and age 2 for G2) and in the second case, with age 3 in Orléans (Fig. 6), they corresponded to the relationships between the traits according to the climate effect modeling (2017 for G1 and 2018 for G2).

The biomass production traits were positively correlated with each other, whether at a genetic or at a phenotypic level. The strongest correlations were observed between both plant heights (above 0.6), between the canopy height and aboveground biomass yield (above 0.7 ) and, above all, between the plant circumference (C50_cm) and aboveground biomass yield (above 0.9).

The biomass composition traits were positively correlated with each other, except hemicelluloses and ash. Relatively strong correlations (above 0.49 ) were mainly highlighted, except for lignin (\%CW) which was less correlated with NDF, cellulose in \%DM and cellulose in $\% \mathrm{CW}$ (from 0.29 to 0.49 ). The correlations were sometimes lower when the biomass composition traits were expressed in \%CW.

Most of the biomass production traits were moderately and positively correlated with the biomass composition traits, the threshold of 0.5 never being exceeded for phenotypic correlations. The relationships were sometimes stronger at a genetic level than at a phenotypic level, especially with NDF, ADF and cellulose (\%DM and \%CW), for which they were sometimes just above the threshold of 0.5. Excepting ash content, the hemicelluloses content (in $\% \mathrm{DM}$ or $\% \mathrm{CW}$ ) was negatively correlated with all the other traits, including biomass production traits.

\section{Discussion}

The genetic parameters of biomass production and composition traits estimated for the $M$. sinensis population, highlighted moderate to high individual plant broad-sense heritability values $\left(H_{s l}^{2}\right)$ according to the age effect per year and the climate effect per age, for each location considered. These values mainly increased over time, depending on genetic, genotype $\mathrm{x}$ age and genotype $\mathrm{x}$ climate interaction variances as well as residual variances. Contrasted climate conditions between the years and identified throughout the plant cycle for each year made it 
possible to explain the high genotype $\mathrm{x}$ climate interaction variance highlighted for some traits. Finally, genetic and phenotypic correlations between biomass production and composition traits were assessed according to specific years and ages. Strong and positive correlations were observed within biomass production traits and within biomass composition traits, except for hemicelluloses, while moderate correlations were highlighted between these two types of traits.

Therefore, three main points will be discussed in this section: (1) the contrast between young and old plant ages for genetic parameters thanks to the staggered-start design and its consequences on the miscanthus breedingcycle; (2) higher heritability values for biomass production traits than biomass composition traits and (3) the moderate correlations observed between biomass production and composition traits.

\section{The contrast between young and old plant ages for genetic parameters thanks to the}

\section{staggered-start design and its consequences on breeding-cycle duration}

Using our staggered-start design, the genotypic and environmental variability was assessed based on genetic variance, genotype $\mathrm{x}$ age and genotype $\mathrm{x}$ climate interaction variances and residual variance. For most traits in both locations, the genetic variance was generally lower for the first year of evaluation according to the age effect (Model 1) or for the first age of evaluation according to the climate effect (Model 2). Accordingly, this variance often increased throughout the years and ages: this can be due to the fact that, while genotypes grow, their differences increase, resulting in higher genetic variability for each trait studied. According to each model, genotype $\mathrm{x}$ age and genotype $\mathrm{x}$ climate interaction variances were highlighted and were larger for young plant ages than for older plant ages, especially for biomass production traits: this was illustrated by the lower ratios of genetic variance to genotype $\mathrm{x}$ age interaction variance and the lower ratios of genetic variance to genotype $\mathrm{x}$ climate interaction variance. However, most of the production traits, especially plant stem number, plant circumference and aboveground biomass yield, also showed large genotype $\mathrm{x}$ age interaction variances for successive years and large genotype $\mathrm{x}$ climate interaction variances for successive ages, in both locations. Biomass composition traits showed large genotype x climate interactions for two successive ages studied in Orléans. These interaction variances rarely overtook the genetic variances in our study, meaning that genetic determinism is mainly led by stable genetic effects for each trait. Nevertheless, those interactions revealed that some genotypes evaluated in the population responded differently: (1) for different plant ages (i.e. the age effect) in the same year, with corresponding climate conditions or (2) in different climate conditions (i.e. the climate effect) for the same age. Segura et al. [42] dissected apple tree architecture into genetic, ontogenetic and environmental effects: in 
accordance with our study, they highlighted genotype $\mathrm{x}$ age and genotype $\mathrm{x}$ year interactions according to a staggered-start design, suggesting specific genetic determinism for ontogenetic and climate effects. Dong et al. [40] considered the genotype $\mathrm{x}$ year interaction to assess the broad-sense heritability of miscanthus production traits and found a substantial effect for plant height, plant circumference and culm-associated traits in one of their mapping populations. Kar et al. [57] evaluated the broad-sense heritability of miscane production traits (i.e. hybrids between sugarcane and miscanthus) and found substantial genotype $\mathrm{x}$ year variances, especially for the stem length and number of stems. Such findings are consistent with our study, even the genotype $\mathrm{x}$ year interaction variances presented in these last studies were not decomposed into age and climate effects as in the present study.

Moderate to high individual plant broad-sense heritability values and high progeny-mean broad-sense heritability values were found for biomass production and composition traits in both locations. The low genetic variances found for the first year or first age evaluated, in combination with large genotype $\mathrm{x}$ age interactions or large genotype $\mathrm{x}$ climate interactions, tend to decrease associated heritability values. Thus, trait heritability values mostly increase throughout years and ages. These observations throughout years or ages were made possible thanks to the staggered-start design established in each location. On the one hand, each single year was evaluated with its corresponding climate (i.e. climate conditions that occurred during the year considered) and the age effect was modeled based on the different ages between G1 and G2 groups. On the other hand, each age was evaluated and the climate effect was modeled according to the different climate conditions between the year considered for G1 and the year considered for G2 (G1 and G2 having the same age). Our results are consistent with the majority of previous studies: Slavov et al. [35] evidenced an increase in broad-sense heritability values for most biomass production and composition traits, by studying an M. sinensis population during three years. Clark et al. [38] evaluated accessions from different miscanthus species in six locations: an increase in broad-sense heritability values was observed for most biomass production traits, when considering broad-sense heritability for all locations between the second and third year. Gifford et al. [39] and Dong et al. [40] also reported higher broad-sense heritability values from year 2 to year 3 after establishment, when considering biomass production traits in $M$. sinensis biparental populations. However, Van der Weijde et al. [58] found that the broad-sense heritability values of biomass composition traits decreased between the second and third year after the establishment on an M. sinensis biparental population. The evolution of heritability estimates is specific to each population and environment tested [59]. As a perennial crop, miscanthus is subjected to changes in conditions from one year to the next, depending on each environment considered. However, such changes highlighted between years can be due to plant age or climate conditions: to our knowledge, the present study is the first to allow the assessment of the broad-sense 
heritability of traits throughout years (i.e. each year with its corresponding climate when the age effect was taken into account) or throughout ages (i.e. each age when the climate effect was taken into account). Broad-sense heritability values are important to consider in a plant-breeding program, in order to start initial selections and provide genetic progress [52]. Because higher broad-sense heritability values were highlighted throughout years and ages, progress through selection would be greater as plants got older, especially for biomass production traits. Accordingly, this increases the duration of the selection process.

This study highlights the advantage of the staggered-start design in decomposing the year effect into climate and age effects to efficiently assess the genetic parameters in the perennial Miscanthus sinensis. In particular, it shows that the genotype $\mathrm{x}$ age and genotype $\mathrm{x}$ climate interaction variances are larger for young plant ages than for old plant ages, especially for biomass production traits. In addition, genetic variance as well as broad-sense heritability values increase across age-spectrums. Such information must therefore be considered as important to miscanthus breeding.

\section{Higher heritability values were observed for biomass production compared to biomass}

\section{composition traits}

Broad-sense heritability values and their means over years or ages were mainly higher for biomass production traits than biomass composition traits. For individual plant broad-sense heritability means over years or ages, biomass production traits were moderately to highly heritable, ranging from 0.42 to 0.62 , while biomass composition traits were moderately heritable and ranged from 0.26 to 0.47 . According to the progeny-mean broadsense heritability means, both types of traits were highly heritable and the trends between them were similar to those of individual plant broad-sense heritability: means ranged from 0.67 to 0.88 for biomass production traits and from 0.60 to 0.80 for biomass composition traits. Contrary to our study, previous studies generally showed that biomass composition traits were more heritable than biomass production traits. According to their $M$. sinensis population evaluated over the course of three years, Slavov et al. [35] found higher broad-sense heritability means for biomass composition traits than biomass production traits, with means of 0.67 and 0.60 , respectively. Petit et al. [60] studied the genetic variability of morphological, flowering and biomass quality traits in hemp (Cannabis sativa L.) in three locations during one season: biomass composition traits were generally more heritable than biomass production traits. 
Thus, the lower broad-sense heritability values observed for the biomass composition traits in our study are

500

501

502

503

504

505

506 probably due to lower variability caused by genetic differences among the progeny (i.e. genetic variance) than for biomass production traits. In addition, it appears that biomass composition traits are frequently more affected by environmental effects (especially when focusing on the residual variance compared to other variances). Broadsense heritability estimates make it possible to predict the response to selection [59]. The higher the heritability, the more the genetic improvement will be possible through breeding. According to the biomass composition traits evaluated in our population, it may take longer than for the biomass production traits to transmit the genetic progress from one generation to the next.

According to the staggered-start design, the means of heritability values over years and ages are higher for biomass production traits than for composition traits. This shows that the potential genetic improvement of biomass production traits is greater in the present study. Biomass composition traits are more affected by multipleenvironment effects, which hamper the expression of the genetic effect in both locations studied. Thus, the improvement of biomass composition traits has to be carefully considered in breeding programs, in order to meet the specific requirements of each bioconversion routes.

\section{Moderate correlations were highlighted between biomass production and composition}

\section{traits}

The genetic and phenotypic correlations showed that biomass production and composition traits were moderately correlated in both locations. Even positive and strong correlations were highlighted within the biomass production traits and within most of the biomass composition traits, for each year according to the age effect (Model 1) or each age according to the climate effect (Model 2), the correlations between both types of traits were moderate. In accordance with our study, Slavov et al. [34] reported moderate correlations between most of the biomass production and composition traits, considering each evaluated year of their M. sinensis population. Petit et al. (2020) [60] also found moderate correlations between biomass production and composition traits in hemp. The correlations among traits provide information about the opportunity to improve a given trait along with another trait, which is potentially possible when the correlation is positive. When negative, the improvement of a trait takes place to the detriment of the other trait considered. Strong correlations can favor the improvement of both traits together, when positive, or be unfavorable when negative. Genetic correlations are most interesting to interpret, because the effect of the environment is not considered [52]. While it would be possible to easily improve biomass production traits or most of the biomass composition traits separately, the improvement of both types of traits 
together would be challenging due to their moderate correlations. In addition, hemicelluloses would be difficult to improve with the other biomass production and composition traits, due to their negative correlations (in \% DM and $\% \mathrm{CW})$. This was also reported by Slavov et al. [34] and Van der Weijde et al. [58]. of the age or climate effect considered. However, the improvement of biomass yield for newly-bred plants is not concomitant of the improvement of their biomass hemicelluloses content. The improvement of biomass production traits does not generate a substantial increase in the other desirable components, due to the moderate genetic correlations observed. Thus, the adjustment of biomass composition traits regarding age and climate conditions must be carefully considered by miscanthus breeders, in order to select a biomass that is suited to the end-use targeted.

\section{Conclusion}

541 In this study, moderate to high individual plant broad-sense heritability and high progeny-mean broad-sense 542 heritability values were assessed for biomass production and composition traits. These heritability values changed 543 in relation to the variance components estimated for each year according to the age effect modeling (Model 1) or 544 each age according to the climate effect modeling (Model 2), when considering each staggered-start design per 545 location. Lower genetic variances associated with substantial genotype $\mathrm{x}$ age and genotype $\mathrm{x}$ climate variances were observed for young plant ages, which tended to decrease heritability values, especially for biomass production traits. Such large interaction variances, compared to genetic variances, were highlighted according to the ratio of genetic variance to genotype $\mathrm{x}$ age interaction variance and the ratio of genetic variance to genotype $\mathrm{x}$ climate interaction variance. Heritability values generally increased through time for most of the traits, which suggested an improved genetic progress when plants get older and implied an increase in the duration of the selection process. However, these values were sometimes lowered by large genotype $\mathrm{x}$ age interaction variances for successive years, especially in the case of the plant stem number, plant circumference and aboveground biomass yield in both locations. Similarly, large genotype $\mathrm{x}$ climate interactions for successive ages were found for most biomass

554 production traits in both locations and biomass composition traits in Orléans.

Overall, biomass production traits were more heritable than biomass composition traits, which means that the response to selection would be better for biomass production traits in our population. Also, even high genetic and phenotypic correlations were highlighted among biomass production and composition traits separately, moderate correlations were diagnosed between biomass production and composition. In contrast, hemicelluloses and ash 
contents were negatively correlated with other traits. Thus, miscanthus breeders have to consider these parameters in order to design breeding programs that follow the requirements of each bioconversion route. The next step of this study will be QTL detection for biomass production and composition traits, while considering the age and climate effects evaluated thanks to the staggered-design in each location.

\section{Acknowledgments}

The authors wish to acknowledge each member of the staff who worked for the establishment and phenotyping of each trial in INRAE experimental stations: GCIE-Picardie team in Estrées-Mons, GBFOr team in Orléans and IJPB team in Versailles. The authors thank Rebecca James who edited the English text.

\section{Declarations}

\section{Funding}

This work has benefited from the support of the Investments for the Future program (grant ANR-11-BTBR-0006BFF) managed by the French National Research Agency (Agence Nationale de la Recherche, ANR).

\section{Competing interests}

The authors have no conflicts of interest to declare that are relevant to the content of this article

\section{Availability of data and material}

Availability of data through GnpIS platform: https://urgi.versailles.inra.fr/Tools/GnpIS

\section{Code availability}

Not applicable

\section{Authors' contributions}

Maryse Brancourt-Hulmel carried out the conception and the design of the study. Emilie Mignot, Stéphanie Arnoult, Laura Fingar, Guillaume Bodineau and Raphaël Raverdy prepared the material and carried out phenotyping data management and collection. Yves Griveau realized NIRS data collection and predictions. Raphaël Raverdy, Maryse Brancourt-Hulmel and Solenne Volant contributed to the analysis of the data. Raphaël Raverdy wrote the manuscript and all authors commented the manuscript. 


\section{Abbreviations}

587 ABM_tDMha: Aboveground biomass yield

588 ADF_\%DM: Acid Detergent Fiber

589 ADL_\%DM - ADL_\%CW: Acid Detergent Lignin

590 Ash_\%DM: Ash

591 CH_cm: Canopy height

592 CGDD: Cumulated growing degree-days

593 CL_\%DM - CL_\%CW: Cellulose

594 CW: Cell wall

595 C50_cm: Plant circumference

596 DM: Dry matter

597 ETPP: Penman potential evapotranspiration

598 GBFOr: Unité expérimentale Génétique Biomasse Forestières Orléans

599 GCIE: Unité expérimentale Grandes Cultures Innovation Environnement

600 GnpIS: Multispecies integrative information system

601 GWAS: Genome-wide association study

$602 \mathrm{H}_{s l}^{2}$ : Individual plant broad-sense heritability

$603 \mathrm{H}_{P i}^{2}$ : Progeny-mean broad-sense heritability

604 HEM_\%DM - HEM_\%CW: Hemicelluloses

605 HMax_cm: Plant maximum height

606 IJPB: Institut Jean-Pierre Bourgin

607 MaxT: Air maximum temperature

608 Mal: Malepartus

609 MeanH: Mean humidity

610 MeanT: Air mean temperature

611 MinT: Air minimum temperature

612 MinTs: Soil minimum temperature

613 NDF_\%DM: Neutral Detergent Fiber

614 PAR: Photosynthetically active radiation

615 PCA: Principal Component Analysis 
620 Sil: Silberspinne

621 URGI: Unité de Recherche Génomique-Info

622 VPD: Vapor-pressure deficit

623 VPD_M: Maximum vapor-pressure deficit

\section{References}

626 1. Foley JA, Ramankutty N, Brauman KA, et al (2011) Solutions for a cultivated planet. Nature 478:337342. https://doi.org/10.1038/nature10452

2. Gabrielle B, Bamière L, Caldes N, et al (2014) Paving the way for sustainable bioenergy in Europe: Energy Rev 33:11-25. https://doi.org/10.1016/j.rser.2014.01.050 experience with a novel energy crop. Biomass and Bioenergy 19:209-227. https://doi.org/10.1016/S0961-9534(00)00032-5

4. Lewandowski I, Scurlock JMO, Lindvall E, Christou M (2003) The development and current status of perennial rhizomatous grasses as energy crops in the US and Europe. Biomass and Bioenergy 25:335361. https://doi.org/10.1016/S0961-9534(03)00030-8

5. Clifton-Brown JC, Stampfl PF, Jones MB (2004) Miscanthus biomass production for energy in Europe and its potential contribution to decreasing fossil fuel carbon emissions. Glob Chang Biol 10:509-518. https://doi.org/10.1111/j.1529-8817.2003.00749.x

640 6. Hastings A, Clifton-Brown J, Wattenbach M, et al (2009) Future energy potential of Miscanthus in Europe. GCB Bioenergy 1:180-196. https://doi.org/10.1111/j.1757-1707.2009.01012.x

642 7. Jones M, Walsh M (2001) Miscanthus for Energy and Fibre. James \& James (Science Publishers) Ltd.

643 8. Heaton EA, Clifton-Brown J, Voigt TB, et al (2004) Miscanthus for renewable energy generation: 
9. Girones J, Vo L, Arnoult S, et al (2016) Miscanthus stem fragment - Reinforced polypropylene

647

648

649

650

651

652

653

654

655

656

657

658

659

660

661

662

663

664

665

666

667

668

669

670

671

672

673

674

675 composites: Development of an optimized preparation procedure at small scale and its validation for differentiating genotypes. Polym Test 55:166-172. https://doi.org/10.1016/j.polymertesting.2016.08.023

10. Acikel H (2011) The use of miscanthus (Giganteus) as a plant fiber in concrete production. Sci Res Essays 6:2660-2667. https://doi.org/10.5897/SRE10.1139

11. Anderson E, Arundale R, Maughan M, et al (2011) Growth and agronomy of Miscanthus $\times$ giganteus for biomass production. Biofuels 2:167-183. https://doi.org/10.4155/bfs.10.80

12. Hodkinson TR, Klaas M, Jones MB, et al (2015) Miscanthus: A case study for the utilization of natural genetic variation. Plant Genet Resour Characterisation Util 13:219-237. https://doi.org/10.1017/S147926211400094X

13. Arnoult S, Brancourt-Hulmel M (2015) A Review on Miscanthus Biomass Production and Composition for Bioenergy Use: Genotypic and Environmental Variability and Implications for Breeding. Bioenergy Res 8:502-526. https://doi.org/10.1007/s12155-014-9524-7

14. Clifton-Brown J, Harfouche A, Casler MD, et al (2018) Breeding progress and preparedness for massscale deployment of perennial lignocellulosic biomass crops switchgrass, miscanthus, willow and poplar. GCB Bioenergy 118-151. https://doi.org/10.1111/gcbb.12566

15. Sacks EJ, Juvik JA, Lin Q, et al (2013) The Gene Pool of Miscanthus Species and Its Improvement. In: Paterson A. (eds) Genomics of the Saccharinae. Plant Genetics and Genomics: Crops and Models, vol 11. Springer, New York, NY

16. Hodkinson TR, Petrunenko E, Klass M, Münnich C (2015) New breeding collections of Miscanthus sinensis, M. sacchariflorus and hybrids from Primorsky Krai, Far Eastern Russia. In: Proceedings of the Biomass 2015: Perennial biomass crops for a resource constrained world, Springer

17. Chae WB, Hong SJ, Gifford JM, et al (2014) Plant morphology, genome size, and SSR markers differentiate five distinct taxonomic groups among accessions in the genus Miscanthus. GCB Bioenergy 6:646-660. https://doi.org/10.1111/gcbb.12101

18. Clifton-brown JC, Chiang Y, Hodkinson TR (2008) Genetic Resources and Breeding Potential to Enhance Bioenergy Production. Genet Improv Bioenergy Crop 249-271. https://doi.org/10.1007/978-0387-70805

19. Sun Q, Lin Q, Yi Z-L, et al (2010) A taxonomic revision of Miscanthus s.l. (Poaceae) from China. Bot J Linn Soc 164:178-220. https://doi.org/10.1111/j.1095-8339.2010.01082.x 
20. Clark L V., Brummer JE, Głowacka K, et al (2014) A footprint of past climate change on the diversity and population structure of Miscanthus sinensis. Ann Bot 114:97-107. https://doi.org/10.1093/aob/mcu084

21. Clark L V., Ryan Stewart J, Nishiwaki A, et al (2015) Genetic structure of Miscanthus sinensis and Miscanthus sacchariflorus in Japan indicates a gradient of bidirectional but asymmetric introgression. J Exp Bot 66:4213-4225. https://doi.org/10.1093/jxb/eru511

22. Clifton-brown JC, Lewandowski I, Andersson B, et al (2001) Performance of 15 Miscanthus genotypes at five sites in Europe. Agron J 93:1013-1019

23. Clifton-Brown JC, Lewandowski I (2002) Screening miscanthus genotypes in field trials to optimise biomass yield and quality in southern germany. Eur J Agron 16:97-110. https://doi.org/10.1016/S11610301(01)00120-4

24. Jezowski S, Głowacka K, Kaczmarek Z (2010) Variation on biomass yield and morphological traits of energy grasses from the genus Miscanthus during the first years of crop establishment. Biomass and Bioenergy 35:814-821. https://doi.org/10.1016/j.biombioe.2010.11.013

25. Anzoua KG, Suzuki K, Fujita S, et al (2015) Evaluation of morphological traits, winter survival and biomass potential in wild Japanese Miscanthus sinensis Anderss. populations in northern Japan. Grassl Sci 61:83-91. https://doi.org/10.1111/grs.12085

26. Arnoult S, Obeuf A, Béthencourt L, Mansard M (2015) Miscanthus clones for cellulosic bioethanol production : Relationships between biomass production, biomass production components, and biomass chemical composition. Ind Crop Prod 63:316-328. https://doi.org/10.1016/j.indcrop.2014.10.011

27. Kaiser CM, Clark L V., Juvik JA, et al (2015) Characterizing a miscanthus germplasm collection for yield, yield components, and genotype $\times$ environment interactions. Crop Sci 55:1978-1994. https://doi.org/10.2135/2014.11.0805

28. Hodgson EM, Lister SJ, Bridgwater A V., et al (2010) Genotypic and environmentally derived variation in the cell wall composition of Miscanthus in relation to its use as a biomass feedstock. Biomass and Bioenergy 34:652-660. https://doi.org/10.1016/j.biombioe.2010.01.008

29. Allison GG, Morris C, Clifton-Brown J, et al (2011) Genotypic variation in cell wall composition in a diverse set of 244 accessions of Miscanthus. Biomass and Bioenergy 35:4740-4747. https://doi.org/10.1016/j.biombioe.2011.10.008

30. Iqbal Y, Lewandowski I (2014) Inter-annual variation in biomass combustion quality traits over five 
years in fifteen Miscanthus genotypes in south Germany. Fuel Process Technol 121:47-55. https://doi.org/10.1016/j.fuproc.2014.01.003

31. Van der Weijde T, Dolstra O, Visser RGF, Trindade LM (2017) Stability of cell wall composition and saccharification efficiency in Miscanthus across diverse environments. Front Plant Sci 7:1-14. https://doi.org/10.3389/fpls.2016.02004

32. Jezowski S (2008) Yield traits of six clones of Miscanthus in the first 3 years following planting in Poland. Ind Crops Prod 27:65-68. https://doi.org/10.1016/j.indcrop.2007.07.013

33. Robson P, Jensen E, Hawkins S, et al (2013) Accelerating the domestication of a bioenergy crop : identifying and modelling morphological targets for sustainable yield increase in Miscanthus. J Exp Bot

34. Slavov GT, Nipper R, Robson P, et al (2013) Genome-wide association studies and prediction of 17

35. Slavov G, Robson P, Jensen E, et al (2013) Contrasting geographic patterns of genetic variation for

36. Nie G, Huang L, Zhang X, et al (2016) Marker-Trait Association for Biomass Yield of Potential Bio-fuel

37. Clark L V, Dzyubenko E, Dzyubenko N, et al (2016) Ecological characteristics and in situ genetic associations for yield-component traits of wild Miscanthus from eastern Russia. Ann Bot 941-955. https://doi.org/10.1093/aob/mcw137

38. Clark L V., Dwiyanti MS, Anzoua KG, et al (2019) Biomass yield in a genetically diverse Miscanthus sinensis germplasm panel evaluated at five locations revealed individuals with exceptional potential. GCB Bioenergy 11:1125-1145. https://doi.org/10.1111/gcbb.12606

39. Gifford JM, Chae WB, Swaminathan K, et al (2015) Mapping the genome of Miscanthus sinensis for QTL associated with biomass productivity. GCB Bioenergy 7:797-810. https://doi.org/10.1111/gcbb.12201 Miscanthus populations. GCB Bioenergy 10:165-185. https://doi.org/10.1111/gcbb.12472 
41. Loughin TM (2006) Improved experimental design and analysis for long-term experiments. Crop Sci 46:2492-2502. https://doi.org/10.2135/cropsci2006.04.0271

42. Segura V, Cilas C, Segura V, et al (2008) Dissecting apple tree architecture into genetic, ontogenetic and environmental effects : mixed linear modelling of repeated spatial and temporal measures. New Phytol. https://doi.org/10.1111/j.1469-8137.2007.02374.x

43. Tejera M, Boersma N, Vanloocke A, et al (2019) Multi-year and Multi-site Establishment of the Perennial Biomass Crop Miscanthus $\times$ giganteus Using a Staggered Start Design to Elucidate N Response. Bioenergy Res 12:471-483. https://doi.org/10.1007/s12155-019-09985-6

44. Zub HW, Arnoult S, Brancourt-Hulmel M (2010) Key traits for biomass production identified in different Miscanthus species at two harvest dates. Biomass and Bioenergy 35:637-651. https://doi.org/10.1016/j.biombioe.2010.10.020

45. Rambaud C, Arnoult S, Bluteau A, et al (2013) Shoot organogenesis in three Miscanthus species and evaluation for genetic uniformity using AFLP analysis. Plant Cell Tissue Organ Cult 113:437-448. https://doi.org/10.1007/s11240-012-0284-9

46. Steinbach D, Alaux M, Amselem J, et al (2013) GnpIS: An information system to integrate genetic and genomic data from plants and fungi. Database 2013:1-9. https://doi.org/10.1093/database/bat058

47. Van Soest PJ, Wine RH (1967) Use of Detergents in the Analysis of Fibrous Feeds. IV. Determination of Plant Cell-Wall Constituents. J AOAC Int 50:50-55. https://doi.org/10.1093/jaoac/50.1.50

48. Henderson CR (1984) Applications of Linear Models in Animal Breeding. Univ Guelph, Guelph

49. Muñoz F, Sanchez L (2019) breedR: Statistical Methods for Forest Genetic Resources Analysts. R package version $0.12-4$

50. Costa e Silva J, Dutkowski GW, Gilmour AR (2001) Analysis of early tree height in forest genetic trials is enhanced by including a spatially correlated residual. Can J For Res 31:1887-1893. https://doi.org/10.1139/cjfr-31-11-1887

51. Akaike H (1974) A new look at the statistical model identification. IEEE Trans Automat Contr 19:716723. https://doi.org/10.1109/TAC.1974.1100705.

52. Gallais A, Poly J (1990) Théorie de la sélection en amélioration des plantes, Masson. Collection Sciences Agronomiques

53. Gouvêa LRL, Silva GAP, Verardi CK, et al (2013) Simultaneous selection of rubber yield and girth growth in young rubber trees. Ind Crops Prod 50:39-43. https://doi.org/10.1016/j.indcrop.2013.06.040 
54. Howe T, Saruul P, Davis J, Chen H (2000) Quantitative genetics of bud phenology, frost damage , and winter survival in an F 2 family of hybrid poplars. 632-642

55. Wei T, Simko V (2017) R package "corrplot": Visualization of a Correlation Matrix (version 0.84)

56. Le S, Josse J, Husson F (2008) FactoMineR: An R Package for Multivariate Analysis. J Stat Softw 25:118. https://doi.org/10.18637/jss.v025.i01

57. Kar S, Weng TY, Nakashima T, et al (2019) Field Performance of Saccharum $\times$ Miscanthus Intergeneric Hybrids (Miscanes) Under Cool Climatic Conditions of Northern Japan. Bioenergy Res. https://doi.org/10.1007/s12155-019-10066-x

58. Van der Weijde T, Kamei CLA, Severing EI, et al (2017) Genetic complexity of miscanthus cell wall composition and biomass quality for biofuels. BMC Genomics 18:1-15. https://doi.org/10.1186/s12864017-3802-7

59. Falconer DS (1981) Introduction to Quantitative Genetics. Ronald Press New York

60. Petit J, Salentijn EMJ, Paulo MJ, et al (2020) Genetic Variability of Morphological, Flowering, and Biomass Quality Traits in Hemp (Cannabis sativa L.). Front Plant Sci 11:1-17. https://doi.org/10.3389/fpls.2020.00102

\section{Illustration Captions}

Fig. 1 For each location considered separately, the corresponding staggered-start design was analyzed according to the age effect modeling per year (a) and the climate effect modeling per age (b). Two models (Model 1 and Model 2) were used, considering a given year or a given age. For example, (a) the year 2017 was considered for G1 and G2, with the age effect modeled according to 3-year-old genotypes in G1 and 2-year-old in G2. In this case, plants of different ages grew in the same climate during a single year. While for example (b), 3-year-old genotypes were considered, according to genotypes of G1 which grew in year 2017 and genotypes of G2 which grew in year 2018. For this case, plants of the same age grew in two different climate conditions, related to each year considered for each group. Below each group name, the group year establishment is specified between brackets

Fig. 2 Individual plant broad-sense $\left(\mathrm{H}_{s l}^{2}\right)$ and progeny-mean broad-sense $\left(\mathrm{H}_{P i}^{2}\right)$ heritability values assessed for each year according to the age effect and considering locations separately. Each heritability value depended on the associated genetic variance, genotype $\mathrm{x}$ age interaction variance and residual variance. The genotype $\mathrm{x}$ age 
interaction variance between G1 and G2 allowed to know the age effect for each year. For example, considering 2016, G1 was 2 years old and G2 was 1 year old. These heritability values (right y-axis) and variance components (left y-axis) were assessed for biomass production (a) and composition (b) traits. See Materials and Methods section for trait name. Blanks in the plots are due to non-available data

Fig. 3 Individual plant broad-sense $\left(\mathrm{H}_{s l}^{2}\right)$ and progeny-mean broad-sense $\left(\mathrm{H}_{P i}^{2}\right)$ heritability values assessed for each age according to the climate effect and considering locations separately. Each heritability value depended on the associated genetic variance, genotype $\mathrm{x}$ climate interaction variance and residual variance. The genotype $\mathrm{x}$ climate interaction variance between G1 and G2 allowed to know the climate effect for each age. For example, plants of age 1 were evaluated for G1 in 2015 and G2 in 2016. These heritability values (right y-axis) and variance components (left y-axis) were assessed for biomass production (a) and composition (b) traits. See Materials and Methods section for trait name. Blanks in the plots are due to non-available data

Fig. 4 (a) and (c) Principal Component Analysis (PCA) plots of the weather indicators for both locations, according to the first and the second principal components, PC1 and PC2, respectively. (b) and (d) Clustering of the coordinates on the two first PCA components of the individuals, for five periods according to four years in two locations. The following indicators were used: air minimum temperature (MinT), air maximum temperature (MaxT), air mean temperature (MeanT), soil minimum temperature (MinTs), mean precipitation (Prec_M), cumulated precipitation (Prec_S), mean humidity (MeanH), vapor-pressure deficit (VPD), maximum vaporpressure deficit (VPD_M), Penman potential evapotranspiration (ETPP), photosynthetically active radiation (PAR) and cumulated growing degree-days (CGDD)

Fig. 5 Genetic and phenotypic correlations (respectively above and below the diagonal) calculated in EstréesMons for the year 2017. Biomass production and composition traits were considered. See Materials and Methods section for trait name. Displayed correlations are significant with a $p$-value $<0.05$, while non-significant correlations are in blanks

Fig. 6 Genetic and phenotypic correlations (respectively above and below the diagonal) calculated in Orléans for the age 3. Biomass production and composition traits were considered. See Materials and Methods section for trait name. Displayed correlations are significant with a $p$-value $<0.05$, while non-significant correlations are in blanks 
822

823

824

825

826

827

828

829

830

831

832

833

834

Table 1 A staggered-start design was established in each of the two locations, Estrées-Mons and Orléans. For each staggered-start design, the number of M. sinensis genotypes per group (G1 and G2) are displayed. Common genotypes between groups within each location are also detailed

Table 2 Characteristics of NIRS calibrations developed for composition traits in miscanthus. Traits considered were Neutral Detergent Fiber (NDF_\%DM), Acid Detergent Fiber (ADF_\%DM), Cellulose (CL_\%DM; CL_\%CW), Hemicelluloses (HEM_\%DM; HEM_\%CW), Acid Detergent Lignin (ADL_\%DM; ADL_\%CW) and Ash content (Ash_\%DM). Traits were expressed according to the percentage of dry matter (\%DM) or the percentage of cell wall $(\% \mathrm{CW})$ of the plants. The standard error of prediction (SEP) is also displayed, with the number $(n)$ of samples used for the calibration and validation steps and the associated correlations (r)

Table 3 For each trait in each year, Model 1 was used to determine the genetic variance $\left(\sigma_{\alpha}^{2}\right)$, the genotype $\mathrm{x}$ age interaction variance $\left(\sigma_{\alpha \beta}^{2}\right)$ and the associated ratio was then computed $\left(\sigma_{\alpha}^{2} / \sigma_{\alpha \beta}^{2}\right)$. Mean individual broad-sense heritability $\left(\mathrm{H}_{s l}^{2}\right)$ was assessed according to the heritability in each year. For each trait in each age, Model 2 was then used to determine the genetic variance $\left(\sigma_{\alpha^{\prime}}^{2}\right)$, the genotype x climate interaction variance $\left(\sigma_{\alpha \prime \gamma}^{2}\right)$ and the associated ratio was also computed $\left(\sigma_{\alpha \prime}^{2} / \sigma_{\alpha \prime \gamma}^{2}\right)$. Bold values are used to highlight results found for young ages. The mean individual broad-sense heritability was determined for each age. Nb. Y: Number of years. Nb. A: number of ages. See Materials and Methods for trait name

\section{Supplemental Data}

Fig. S1 Spatial effects illustrated for (a) Plant maximum height (HMax_cm), (b) Aboveground biomass yield (ABM_tDMha) and (c) Cellulose (CL_\%DM) in Estrées-Mons for plants of year 2017. These effects were determined using the $\mathrm{x}$-axis and $\mathrm{y}$-axis coordinates of the field, in each model assessed with breedR software. Legend with " $z$ " represents the values of spatial effects: red color for positive effects, white for neutral effects and blue for negative effects

Fig. S2 Individual plant broad-sense $\left(\mathrm{H}_{s l}^{2}\right)$ and progeny-mean broad-sense $\left(\mathrm{H}_{P i}^{2}\right)$ heritability values assessed for each year according to the age effect (Model 1) and for each age according to the climate effect (Model 2) and considering locations separately. These heritability values (right y-axis) and variance components (left y-axis) were assessed for biomass composition traits expressed in \% $\mathrm{CW}$ and for ash content (Ash_\%DM). Blanks in the plots are due to non-available data 
850 Table S1 Individual plant broad-sense heritability values $\left(\mathrm{H}_{s l}^{2}\right)$ and progeny-mean broad-sense heritability values

$851\left(\mathrm{H}_{P i}^{2}\right)$ for each year according to the age effect (Model 1) and for each age according to the climate effect (Model

852 2). Means of each heritability were computed for successive years or successive ages, considering each location

853 separately. Nb. Y: Number of years. Nb. A: number of ages

854 Table S2 Description of the five periods used to assess the weather indicators. Each growth stage date (in calendar

855 day number) was determined by mean Malepartus growth stages for each location

856 Table S3 Mean values of weather indicators assessed in five periods for four years in two locations (a. and b.).

857 The following indicators were used: air minimum temperature (MinT), air maximum temperature (MaxT), air 858 mean temperature (MeanT), soil minimum temperature (MinTs), mean precipitation (Prec_M), cumulated 859 precipitation (Prec_S), mean humidity (MeanH), vapor-pressure deficit (VPD), maximum vapor-pressure deficit 860 (VPD_M), Penman potential evapotranspiration (ETPP), photosynthetically active radiation (PAR) and cumulated 861 growing degree-days (CGDD)

862

863

864 


\section{Figures}

a. Age effect modelling

per Year

Model 1

b. Climate effect modelling per Age

Model 2

\begin{tabular}{c|c|cccc|} 
G1 & Year & 2015 & 2016 & 2017 & 2018 \\
$(2014)$ & Age & 1 & 2 & 3 & 4
\end{tabular} \mid
\begin{tabular}{c|c|cccc|} 
G2 & Year & - & 2016 & 2017 & 2018 \\
$(2015)$ & Age & - & 1 & 2 & 3
\end{tabular} \mid

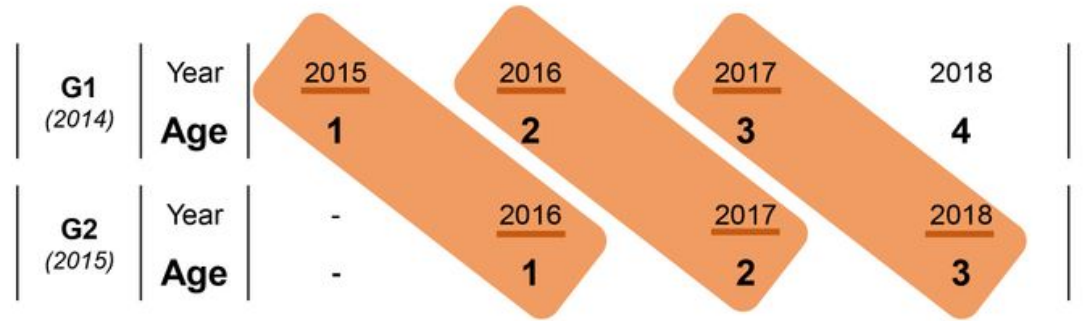

\section{Figure 1}

For each location considered separately, the corresponding staggered-start design was analyzed according to the age effect modeling per year (a) and the climate effect modeling per age (b). Two models (Model 1 and Model 2) were used, considering a given year or a given age. For example, (a) the year 2017 was considered for G1 and G2, with the age effect modeled according to 3-year-old genotypes in G1 and 2-year-old in G2. In this case, plants of different ages grew in the same climate during a single year. While for example (b), 3-year-old genotypes were considered, according to genotypes of G1 which grew in year 2017 and genotypes of $\mathrm{G} 2$ which grew in year 2018. For this case, plants of the same age grew in two different climate conditions, related to each year considered for each group. Below each group name, the group year establishment is specified between brackets 
a. PRODUCTION TRAITS

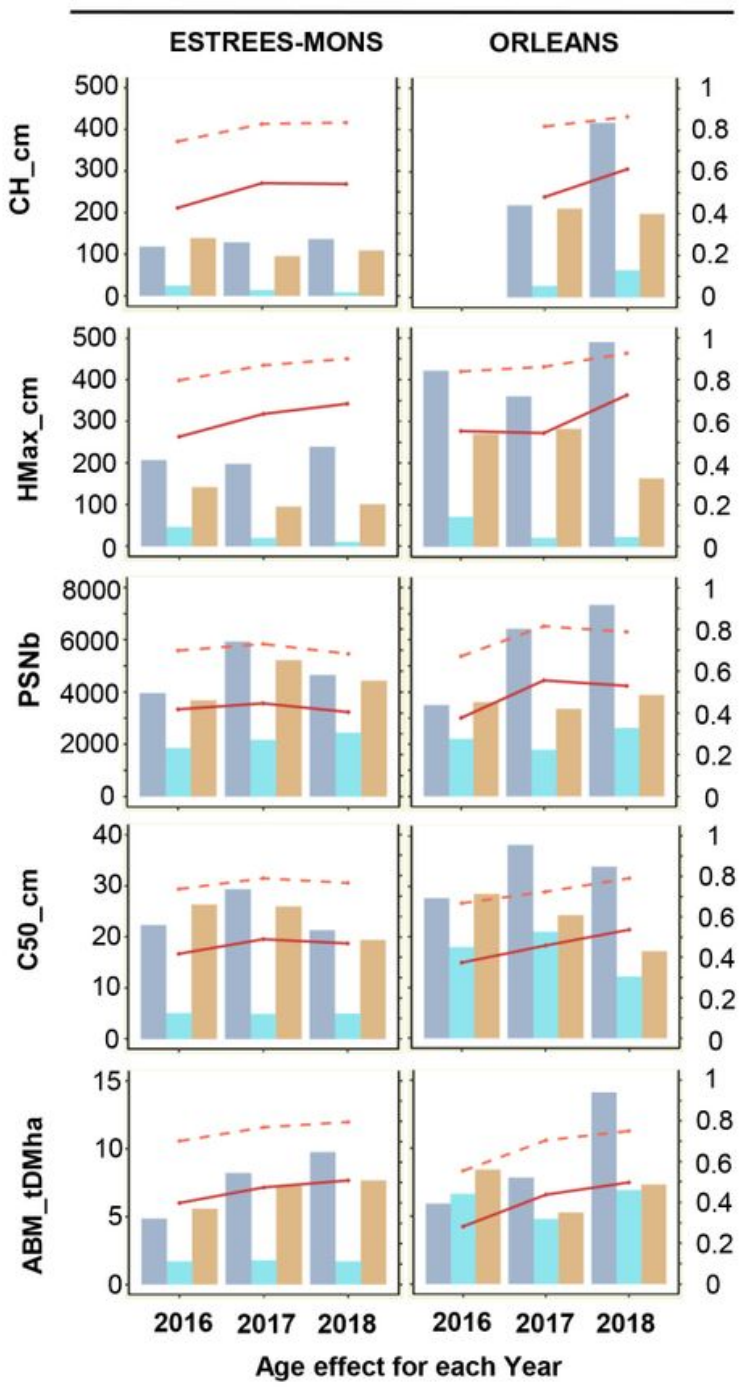

b. COMPOSITION TRAITS

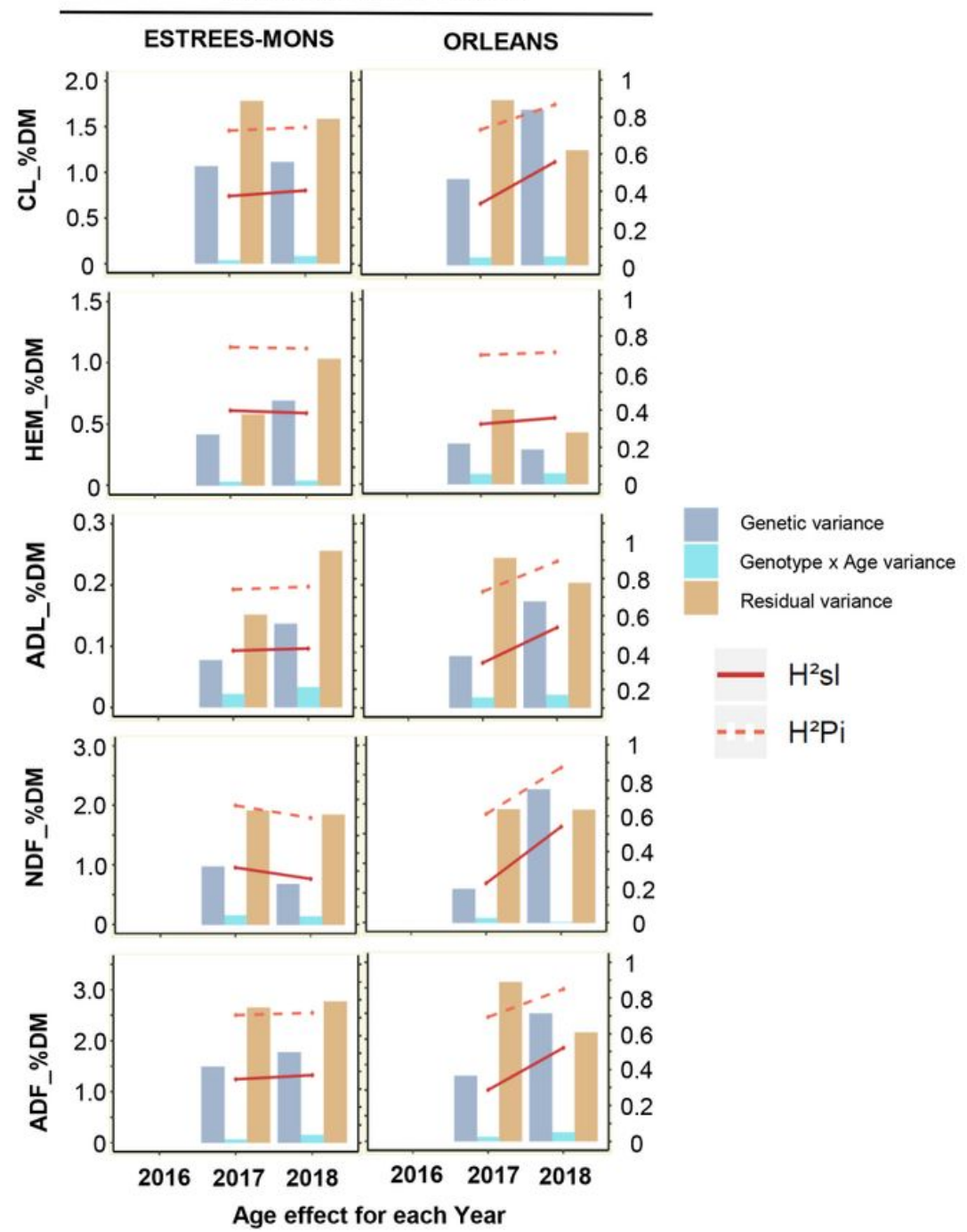

Figure 2

Individual plant broad-sense ( $\mathrm{H} 2 \mathrm{sl})$ and progeny-mean broad-sense (H2pi)

heritability values assessed for each year according to the age effect and considering locations separately. Each heritability value depended on the associated genetic variance, genotype $x$ age interaction variance and residual variance. The genotype $x$ age interaction variance between $G 1$ and $G 2$ allowed to know the age effect for each year. For example, considering 2016, G1 was 2 years old and G2 was 1 year old. These heritability values (right y-axis) and variance components (left y-axis) were assessed for biomass production (a) and composition (b) traits. See Materials and Methods section for trait name. Blanks in the plots are due to non-available data 
a. PRODUCTION TRAITS

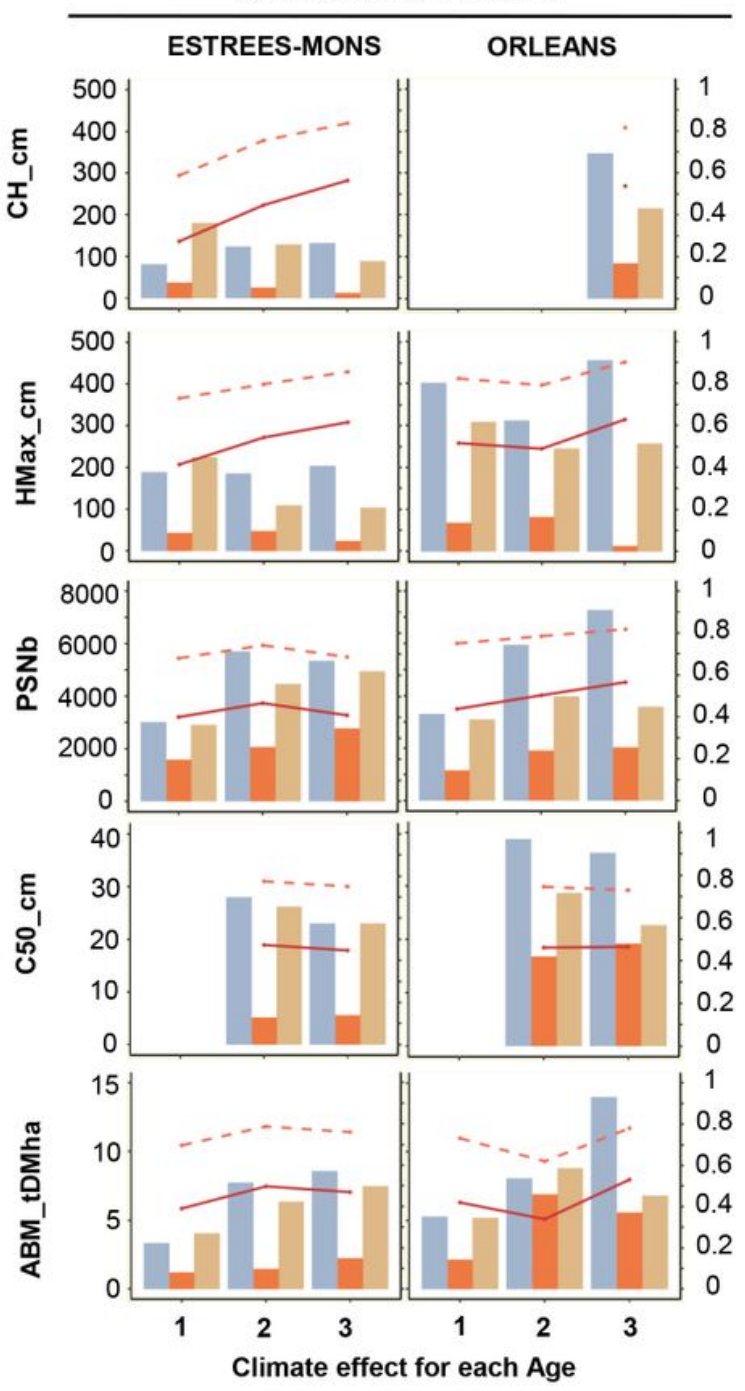

b. COMPOSITION TRAITS

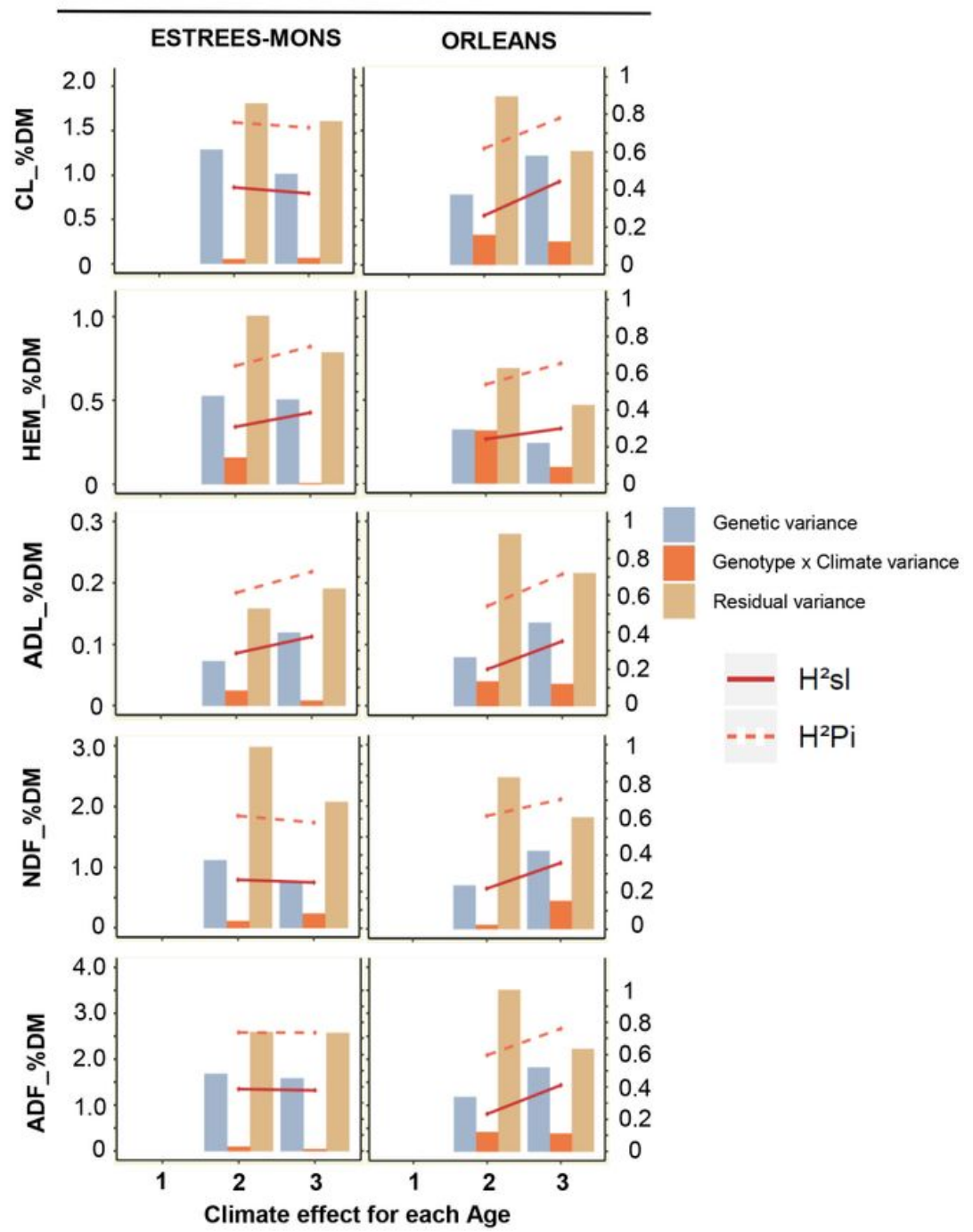

\section{Figure 3}

Individual plant broad-sense ( $\mathrm{H} 2 \mathrm{sl})$ and progeny-mean broad-sense (H2pi)

heritability values assessed for each age according to the climate effect and considering locations separately. Each heritability value depended on the associated genetic variance, genotype $x$ climate interaction variance and residual variance. The genotype $\mathrm{x}$ climate interaction variance between $\mathrm{G} 1$ and G2 allowed to know the climate effect for each age. For example, plants of age 1 were evaluated for $\mathrm{G} 1$ in 2015 and $\mathrm{G} 2$ in 2016. These heritability values (right y-axis) and variance components (left y-axis) were assessed for biomass production (a) and composition (b) traits. See Materials and Methods section for trait name. Blanks in the plots are due to non-available data 

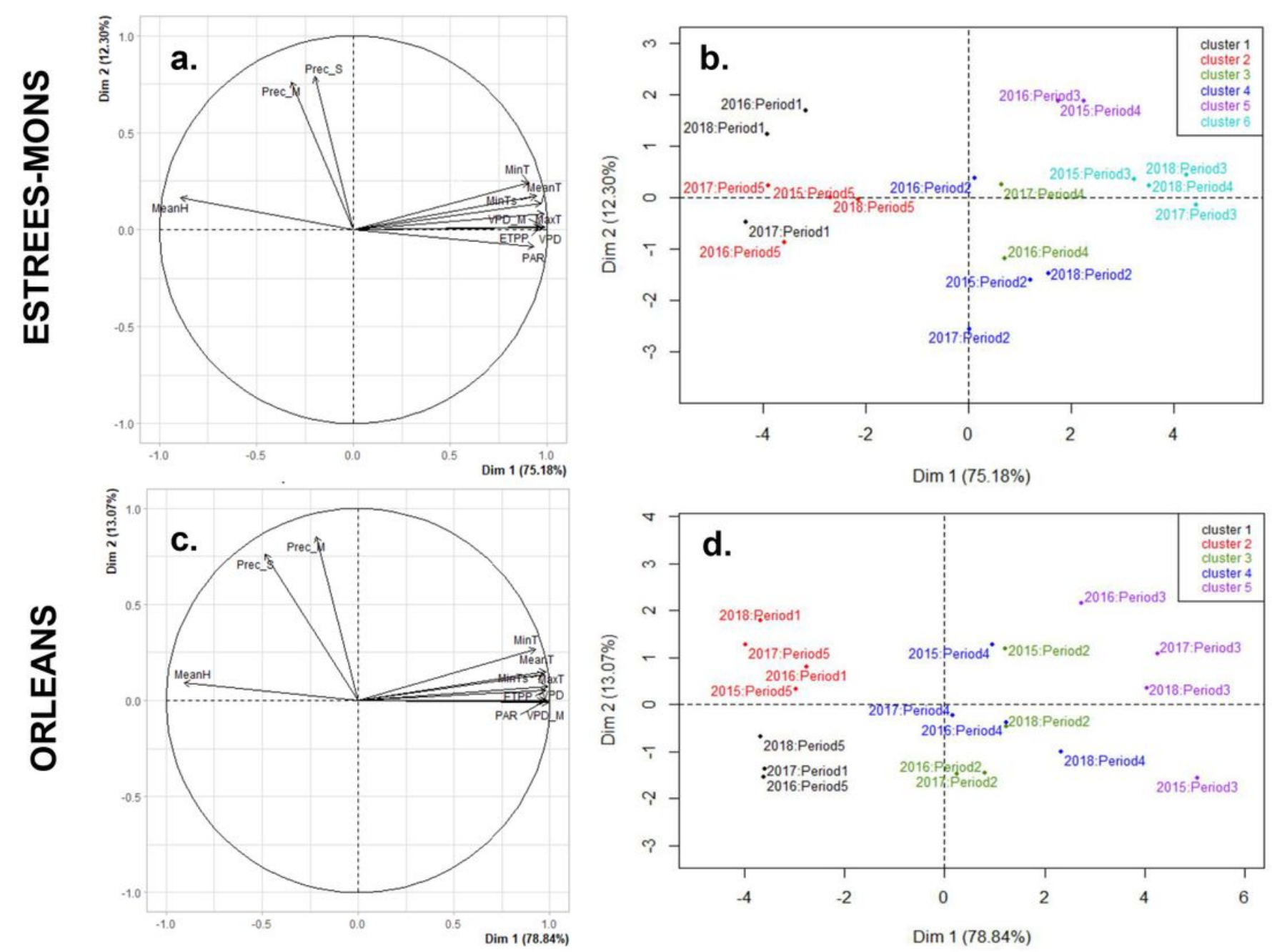

Figure 4

(a) and (c) Principal Component Analysis (PCA) plots of the weather indicators for both locations, according to the first and the second principal components, PC1 and PC2, respectively. (b) and (d) Clustering of the coordinates on the two first PCA components of the individuals, for five periods according to four years in two locations. The following indicators were used: air minimum temperature (MinT), air maximum temperature (MaxT), air mean temperature (MeanT), soil minimum temperature (MinTs), mean precipitation (Prec_M), cumulated precipitation (Prec_S), mean humidity (MeanH), vaporpressure deficit (VPD), maximum vapor-pressure deficit (VPD_M), Penman potential evapotranspiration (ETPP), photosynthetically active radiation (PAR) and cumulated growing degree-days (CGDD) 


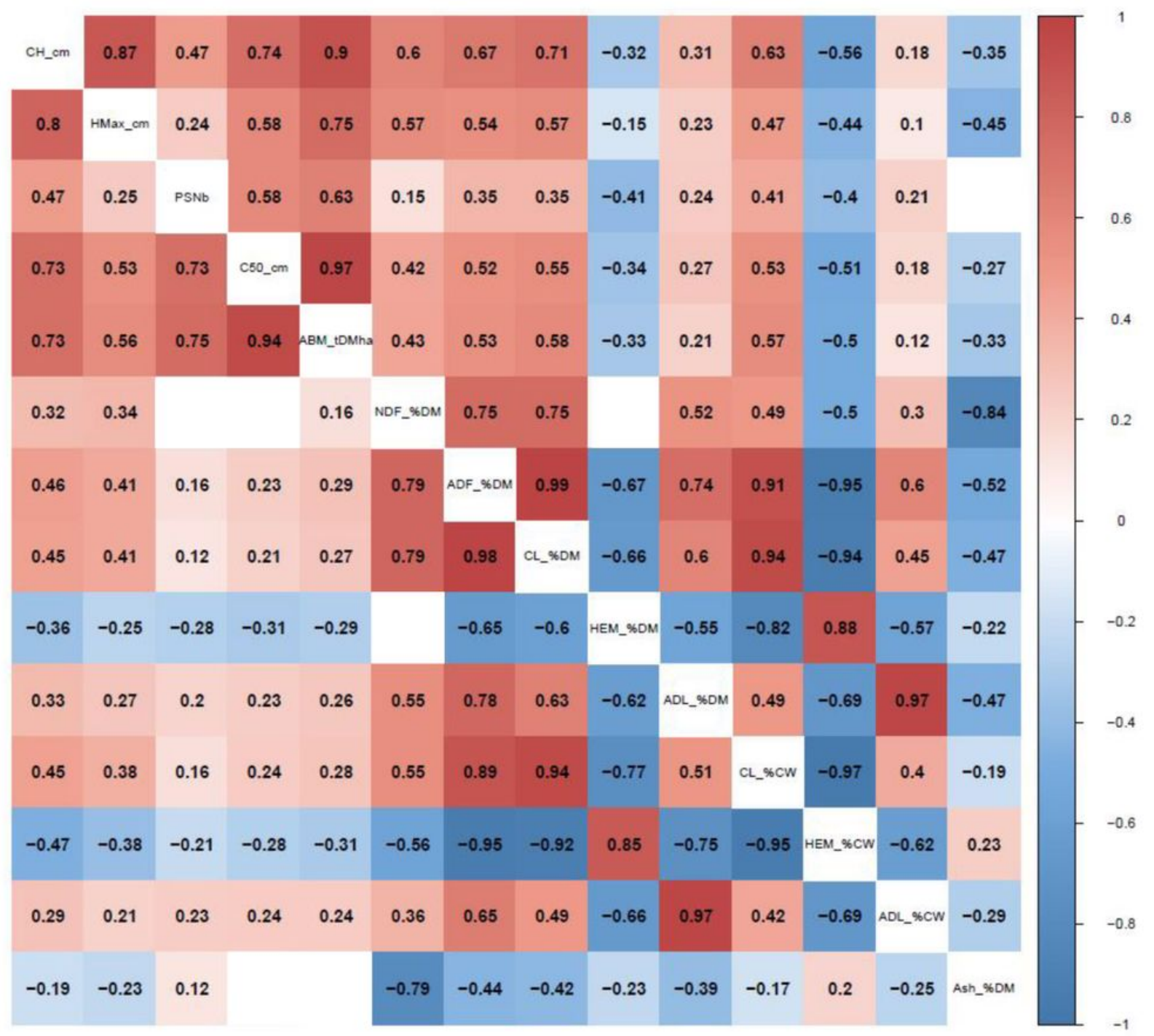

\section{Figure 5}

Genetic and phenotypic correlations (respectively above and below the diagonal) calculated in EstréesMons for the year 2017. Biomass production and composition traits were considered. See Materials and Methods section for trait name. Displayed correlations are significant with a $p$-value $<0.05$, while nonsignificant correlations are in blanks 


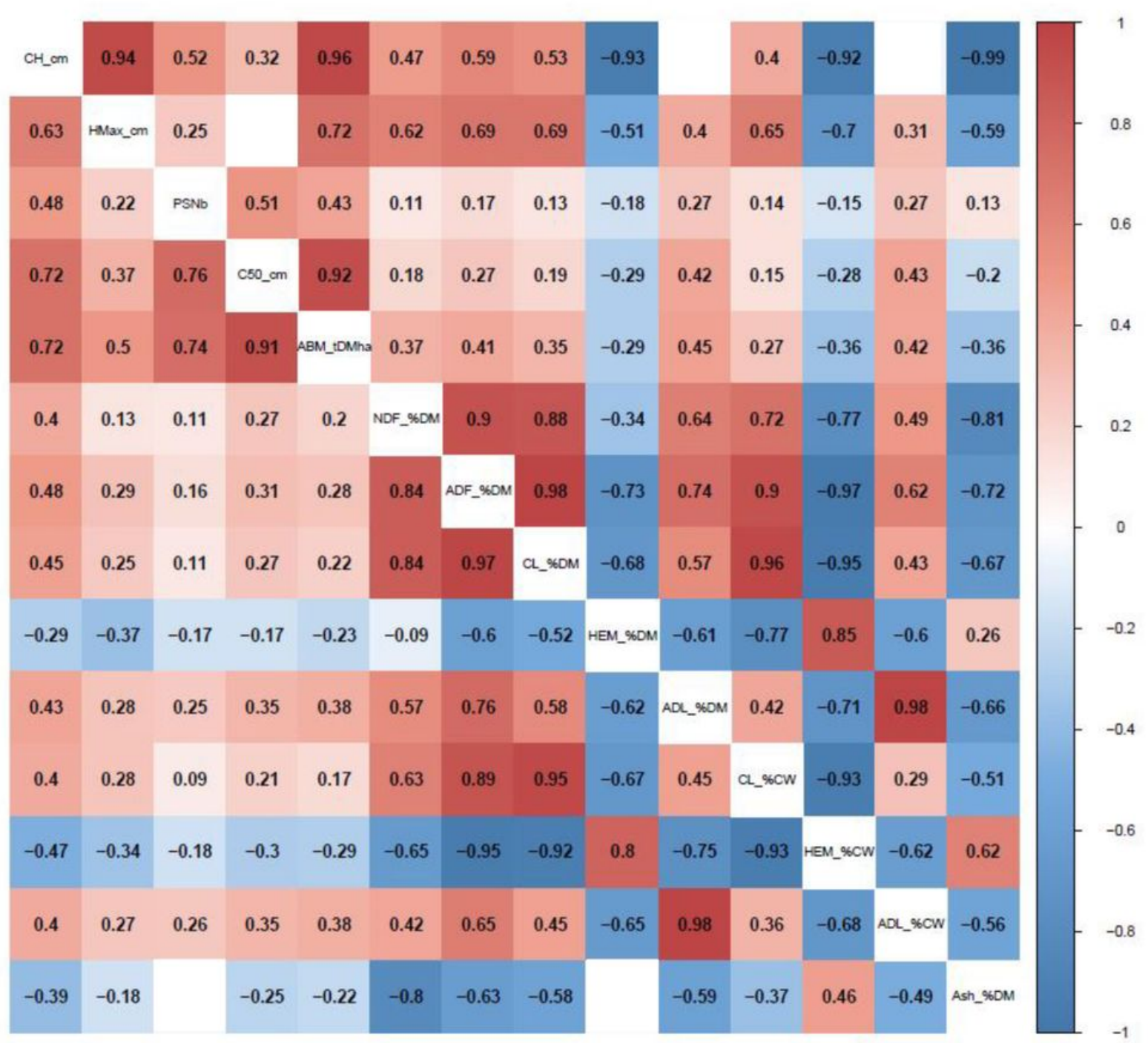

\section{Figure 6}

Genetic and phenotypic correlations (respectively above and below the diagonal) calculated in Orléans for the age 3. Biomass production and composition traits were considered. See Materials and Methods section for trait name. Displayed correlations are significant with a $p$-value $<0.05$, while non-significant correlations are in blanks

\section{Supplementary Files}

This is a list of supplementary files associated with this preprint. Click to download.

- FigureS1.pdf

- Figures2.pdf

- Tables1.docx

- Tables2.docx 
- Tables3.docx 